\title{
Book Review Atmosphere Pollution
}

\author{
Ecozone, Iasi, Romania, ISBN 978-606-8625-02-7, 2019, 2 volumes
}

\section{Authors: LILIANA LAZAR AND ION BALASANIAN}

The book "Atmospheric Pollution", offered for publication by Assoc. Prof. Liliana Lazăr and Prof.univ.dr.ing. Ion Balasanian is a guide that aims to guide students and specialists in the field of engineering, in the correct and organized assimilation of basic notions regarding both the foundations of the atmosphere and its pollution, from an interdisciplinary perspective, in order to highlight the importance of this factor on the quality of life.

In this context, the book presents during two volumes and 6 chapters, the most important aspects related to the fundaments of the atmosphere, pollutants and processes that cause air pollution, and the dispersion and transport of pollutants in the atmosphere. At the end of each chapter is mentioned the list of references used in the design of the material. Thus, in Chapter 1 are presented in detail aspects related to the composition and structure of the atmosphere, the quantities and state transformations used to characterize the atmospheric air, atmospheric phenomena and its energy balance. Chapter 2 presents the main sources of air pollution and its most important pollutants, both from the perspective of chemical engineering and from the perspective of environmental engineering. Chapter 3 allocates a large space to chemical pollution of the atmosphere, by presenting the main inorganic gases, volatile organic compounds and particulate matter, which have a significant contribution to this phenomenon. In each case, both the effects that pollutants have on atmospheric air quality and the main industrial sources responsible for chemical pollution of the atmosphere are presented. Chapter 4 addresses physical air pollution. Thus, noise pollution, electromagnetic pollution, pollution with radiation from electrical installations, pollution with microwave radiation, radioactive radiation or X-ray radiation are presented in detail, in an interdisciplinary manner, which took into account both the review of their most important properties and their effects on the environment and human health. Chapter 5 deals with the most important phenomena caused by air pollution. Climate change, the greenhouse effect and global warming, radioactive forcing, ozone depletion, smog, acid rain and deposits, reduced atmospheric visibility, etc., are particularly important and current issues at national and international level, which are described in detail in this chapter, from an interdisciplinary perspective. Chapter 6 presents the dispersion and transport of pollutants in the atmosphere. Starting from the evolutionary models of the atmosphere, the authors describe how climatic factors influence the dispersion of pollutants in the atmosphere, and present the most important models of pollutant dispersion, in a logical and engineering way.

From our point of view, this monograph provides a systematized description of the most important problems related to air pollution, which will be of real use to tomorrow's specialists to design and implement clean production technologies, in accordance with the principles of sustainable development. Through the content offered for publication, the authors emphasize the role that air pollution plays in industrial development, and emphasize the importance that environmental pollution (air pollution, in this case) has on the training of future specialists (engineers and not only), responsible for carrying out production activities.

The material offered for analysis, although very extensive and rich, is explicit, simple in address and systematic, and presents an extremely rigorous and inspired selection of the most important aspects related to air pollution, in an intelligently designed and interdisciplinary manner. All the notions in this manuscript are presented clearly, concisely, with eloquent comments and examples 
(figures, tables, diagrams and schemes) for a clearer understanding, according to the needs of the reader. That is why we consider that, apart from the students to whom it is addressed, the book is an excellent means of information and a real help for specialists in other fields who need detailed knowledge related to air pollution.

In conclusion, the book has not only achieved its goal, but can go beyond the limits imposed by the authors, making it possible for people to access it, who need a renewal of information or a didactic and systematic look at the processes and especially the effects that air pollution has on human health and the quality of the environment.

Through its intrinsic quality, through the simple and intelligent means of presentation, through the technical quality of the writing and through the quality of the language (specialized or Romanian language), the book can be published and will certainly be one of the notable achievements in this field.

Prof.dr.habil.chem. Laura Bulgariu

Prof. dr.eng. Ion Mamaligă

Gheorghe Asachi Technical University of Iasi

"Cristofor Simionescu" Faculty of Chemical Engineering and Environmental Protection 